\title{
A RELIGIÃO NA AMAZÔNIA E A QUESTÃo EPISTEMOLÓGICA SOBRE NATUREZA E CULTURA: UMA REFLEXÃO SOBRE A RELIGIOSIDADE POPULAR.
}

\author{
José Maria Guimarães Ramos ${ }^{1}$
}

\begin{abstract}
RESUMO
O presente artigo é uma reflexão sobre o tema natureza e cultura relacionado como a religiosidade popular, mas especificamente sobre testemunhos de milagres que é objeto de minhas pesquisas há vários anos. O tema traz a questão epistemológica porque, a partir da religiosidade, faço duas novas reflexões em minhas pesquisas sobre o assunto, onde já tinha analisado com as teorias de Victor Turner e Mircea Eliade ${ }^{2}$. Metodologicamente este trabalho é uma reflexão para fugir da dicotomia natureza e cultura na composição da religiosidade popular amazônica, a partir de duas ideias, a saber, a ideia de Amazônia antropogênica que é a visão que a natureza e o humano se forjam mutuamente e a ideia do perspectivismo, que neste caso, tento mostrar que o ser humano amazônico se relaciona tanto com a natureza, quanto com os seres espirituais do catolicismo que são os santos e a Virgem Maria, compondo três mundos, o humano ou social, o natural e o espiritual, um exemplo disso são os testemunhos de milagres.
\end{abstract}

Palavras-chave: Religiosidade popular. Amazônia. Perspectivismo.

\begin{abstract}
Este artículo es una reflexión sobre el tema naturaleza y cultura relacionados con la religiosidad popular, pero específicamente sobre testimonios de milagros que han sido objeto de mi investigación durante varios años. El tema trae la pregunta epistemológica porque, basado en la religiosidad, hago dos nuevas reflexiones en mi investigación sobre el tema, donde ya había analizado con las teorías de Victor Turner y Mircea Eliade. Metodológicamente, este trabajo es un reflejo para escapar de la naturaleza y cultura de la dicotomía en la composición de la religiosidad popular amazónica, a partir de dos ideas, a saber, la idea de la Amazonía antropogénica, que es la visión de que la naturaleza y el ser humano se forjan mutuamente y la idea del perspectivismo, que en este caso trato de mostrar que el ser humano amazónico está relacionado tanto con la naturaleza como con los seres espirituales del catolicismo que son los santos y la Virgen María, componiendo tres mundos, el humano o el social, el natural y el natural. Un ejemplo de esto es el testimonio de los milagros.
\end{abstract}

Palabras clave: Religiosidad popular. Amazon Perspectivismo.

\footnotetext{
${ }^{1}$ Graduado em Filosofia. Graduado em Teologia pela Pontifícia Universidade Regina Apostolorum de Roma. Especialista em Antropologia Filosófica. Mestre em Ciências da Religião. Doutorando em Sociologia e Antropologia pelo PPGSA-UFPA. Professor Substituto de Filosofia - UEPA. Professor de Filosofia - SEDUCPA.

${ }^{2}$ Cf: RAMOS, José Maria Guimarães. A Aparição de Nossa Senhora de Nazaré em Belém do Pará: o sagrado na Amazônia. Belém: Paka-Tatu, 2018.
} 


\section{INTRODUÇÃO}

O tema deste artigo traz a questão epistemológica sobre o tema da natureza e cultura como uma tentativa de alargar o horizonte compreensivo de questões amazônicas já muito discutidas por diversas teorias clássicas. A tentativa é de usar o perspectivismo indígena para refletir a religiosidade popular. Não é a primeira vez que o perspectivismo de Viveiros de Castro é usado para analisar questões não indígenas, Heraldo Maués, por exemplo, usou tal teoria para refletir sobre temas amazônicos como os encantados, isto me instigou a pensar questões da religiosidade popular que forja uma visão de mundo em que os santos católicos são parte essencial.

Nos últimos anos a questão epistemológica sobre a relação entre natureza e cultura teve avanços tanto em âmbito teórico como metodológico, no sentido de eliminar dicotomias que sempre levavam a embates improdutivos ou a problemas irresolúveis sobre como a cultura e a natureza influenciam na vida de sociedades humanas. Philippe Descola, Tim Ingold e Viveiros de Castro são alguns nomes importantes que fizeram avançar a reflexão sobre natureza e cultura não seguindo os pressupostos dicotômicos tradicionais do estruturalismo e funcionalismo ou da fenomenologia, por exemplo.

Esses pensadores mostraram que natureza e cultura não são basicamente antagônicas, mas dois aspectos de um mesma realidade que é a vida humana em sociedade dentro de um ambiente determinado que interage com o homem sem demarcações visíveis entre o humano e o não humano, ou seja, a natureza e realidades simbólicas sejam elas sociais ou religiosas. Essa postura teórica ajuda a alargar o horizonte da compreensão da sociedade e sua relação como a natureza de modo que as categorias êmicas não sejam tratadas de forma instrumental como no funcionalismo, mas como parte da cosmologia local e como categorias epistemológicas propriamente ditas, fonte de conhecimento e não somente categorias de análise interpretativa.

Nesse sentido, o objetivo deste artigo é olhar para a religiosidade popular amazônica nesta perspectiva para perceber como a natureza da Amazônia interage com o humano forjando categorias, ritos e símbolos religiosos oriundos da relação natureza e sociedade. Tal dicotomia entre natureza e cultura na Amazônia foi evada ao extremo, como se vê, na literatura do início do século XX que retrata a floresta como "inferno verde"3, ou seja, uma

\footnotetext{
${ }^{3}$ Como um inferno verde é descrita a exuberante natureza amazônica na literatura de Alberto Rangel e Euclides da Cunha.
} 
natureza exuberante e descomunal frente à qual o humano desventurado e diminuto não pode interferir por sua suposta incapacidade de interagir com tal força natural.

Esta visão negativa junto com a ideia da filosofia moderna de domínio da natureza ajudou a formar um imaginário antiecológico que norteou os projetos de desenvolvimento da região, que resultou em projetos de exploração dos recurso naturais, que hoje é um tema caro da antropologia ecológica. Uma análise da simbologia religiosa desconstrói essa ideia, visto que a natureza é o palco onde as cenas da vida cotidiana acontecem, é o lugar de encontro do humana e do não humano, em que a natureza divide o protagonismo como o homem na formação de sua vida social.

\section{A AMAZÔNIA ANTROPOGÊNICA E A REFLEXÃO ANTROPOLÓGICA ENTRE NATUREZA E CULTURA}

A natureza amazônica sempre esteve no foco dos estudos das diversas disciplinas que se voltam para a região, o motivo é muito claro pois trata-se da maior biodiversidade do planeta. A exuberância da natureza e a preocupação com sua exploração e preservação são sempre temas importantes que atraem a atenção dos estudos ecológicos, mas no século XX paulatinamente, sobretudo com estudos arqueológicos, percebeu-se as implicações antropogênicas na formação do ambiente natural, de como a atividade humana influenciou sobre o meio desde aproximadamente há 11 mil anos e deste modo começou a se perceber a importância da ação social na formação da paisagem amazônica.

Os arqueólogos foram de grande importância para difundir no meio científico a ideia de uma "Amazônia antropogênica, isto é, de uma Amazônia com matas conscientemente cultivadas" (MAGALHÃES, 2016: 12), de um espaço que sofreu alterações de indivíduos e grupos de indivíduos que pelo ponto de vista da antropologia social de matriz evolucionista faziam parte como telespectadores das vicissitudes históricas em evolução, as descobertas arqueológicas apontaram para uma outra direção, "tentaram romper com o antigo historicismo linear universal e com o relativismo fragmentário sem sujeito e sem história das ciências sociais radicalmente modernas" (MAGALHÃES, 2016: 16). Essa perspectiva tem o seguinte pressuposto:

[...] Como as antigas culturas amazônicas influenciaram a formação e distribuição de recursos vegetais ainda hoje disponíveis e úteis para as populações [...]. Em resumo, a ideia de que só florestas naturais primárias se desenvolveram em ambientes sem influência humana, não se sustenta pois haveria florestas de origem cultural que também se desenvolveram como florestas primárias. Por serem antropogenicamente consolidadas, as ações antrópicas teriam surgido em períodos históricos muito recuados e hoje essas florestas se sustentariam e multiplicar-se-iam naturalmente, 
sem a necessidade da intervenção consciente ou inconsciente do ser humano (MAGALHÃES, 2016: 11).

Deste modo, a formação cultural estabeleceu-se em relação indissociável com os elementos naturais que compõem o ambiente, em que a natureza não somente é a fornecedora dos meios de subsistência, em que o meio de produção material determine a formação cultural, mas a própria natureza sofre intervenção em seu aspecto físico. Pensar uma Amazônia antropogênica é rejeitar a ideia de que o fator natural se sobrepõe ao humano, pois mostra que a adaptação do homem aos vários ambientes do território como áreas de várzeas, terra firme ou margens de rios, passou-se de forma rápida que deu origem uma cultura adaptada ao meio ambiente, como se vê em seguida:

[...] que populações caçadoras-coletoras e ou pescadoras, com diferentes níveis de complexidade e alinhadas aos ecossistemas da floresta tropical amazônica estão incluídas no processo histórico da Cultura Tropical, quando deram início à antropogênese amazônica. [...] Assim, teria sido no âmbito da Cultura Tropical que essas populações (incluindo aí também as pescadoras), relativamente mais homogêneas e nômades iniciaram, de modo constante e produtivo, o manejo dos recursos florestais. E ainda que teriam sido eles, através dos processos históricos da Cultura Tropical que conquistaram e desenvolveram a tecnologia de produção da cerâmica e iniciaram a domesticação de algumas plantas. Finalmente, que as populações agricultoras posteriores, nada mais seriam do que as herdeiras naturais das populações caçadoras-coletoras pioneiras, as quais, através de um novo modo de produção, fundaram o processo histórico a Cultura Neotropical (MAGALHÃES, 2016: 246-247).

Esta concepção vai ao encontro da perspectiva antropológica sobre o importante papel da natureza e do meio ambiente no plano social e vice-versa, como pressuposto genuinamente ecológico como sustenta Tim Ingold (2001: 38) que estabeleça a intenção e a ação humana no contexto de uma relação permanente e mutuamente constitutiva entre o agente e seu meio ambiente. Isto quer dizer que nem o social nem o natural, nessas condições, não se desenvolvem de maneira exclusivamente autônoma ao ponto de uma se sobrepor a outra.

Reconhecer isto é importante e, ao mesmo tempo, um desafio para a teoria antropológica como disse Descola e Pálsson (2001: 27) que o reconhecimento de que a natureza é uma construção social e de que as conceitualizações do meio ambiente são produtos de contextos históricos e especificidades culturais em contínua mudança apresenta um desafio difícil da indagação antropológica. Mas esse desafio de pensar natureza e cultura sem dicotomias levou a estudos mais plausíveis para se compreender o desenvolvimento cultural e biológico do humano em teorias clássicas coma a da seleção natural de Darwin. 
Segundo Tim Ingold (2001: 47) a razão e a natureza são agentes de seleção, e que isto oferece explicação para o surgimento de crenças e preferências, que segundo o autor, têm origem nas intenções humanas que podem ter surgido ao longo de uma história de seleção natural.

Estes estudos mostram que no âmbito epistemológico também é salutar superar dicotomias e que deve haver uma aproximação maior das ciências da natureza e das ciências sociais, pois as estratégias de sociabilidade humana não estão desligadas de seu desenvolvimento biológico. Segundo Tim Ingold (2001: 48, Minha tradução), "se se considera que as estratégias são produto do raciocínio humano, também temos que recorrer à seleção natural para explicar a racionalidade das estratégias". Isto requer uma visão mais ampla para compreender o desenvolvimento de uma sociedade sem prescindir dos aspectos naturais que a influenciam.

Esse posicionamento epistemológico é fundamental para o objetivo deste artigo, isto é, de pensar a religiosidade popular na Amazônia, uma religiosidade que também, como todo o sistema cultural, recebeu influências naturais de seu meio ambiente e que não se pode pensar a religiosidade sem o elemento natureza. $\mathrm{O}$ interessante dessa perspectiva é colocar o natural na categoria do não humano.

\section{A CATEGORIA dO NÃO HUMANO, ALGUNS ASPECTOS AMAZÔNICOS}

O Boto é uma narrativa amazônica de um golfinho encantado que ao entardecer transforma-se em um belo rapaz que seduz as moças e as engravida. A lenda do Boto é um exemplo de como a fronteira do humano e do não humano na Amazônia é flexível, e no caso do Boto, é difícil de ser delimitada. O filho do Boto tem significado ontológico, ele possui "uma dupla natureza: é humano e encantado" (LOUREIRO, 2007: 39), o humano e o não humano neste caso fazem parte do mesmo ser. Assim, o imaginário amazônico se constitui e as explicações funcional-estruturalista da antropologia social clássica encontram seu limite. Esta lenda é um exemplo de como a natureza é humanizada, de como ela é um elemento socialmente construído e de tal construção tira seu significado, longe de ser simplesmente uma res extensa cartesiana.

Na linha de que a concepção da natureza é algo social encontra-se uma boa parte da discussão epistemológica atual, na antropologia destaca-se, entre outros, Phiilippe Descola. Segundo ele esta visão: 
Também foi produto de estudos etnográficos realizados por antropólogos que compreenderam que a dicotomia natureza e cultura era uma ferramenta inadequada ou errônea para dar conta de modos em que as pessoas que eles estudavam falavam de seu meio ambiente físico e interagiam com ele. Comumente, essas pessoas não só atribuíam disposições e comportamentos humanos a plantas ou animais - um dos mais antigos enigmas da antropologia -, e mais ainda, frequentemente expandiam o reino do que para nós são organismos não viventes para incluir espíritos, monstros, objetos, minerais ou qualquer entidade dotada de propriedades definidas como uma consciência, uma alma, uma capacidade de comunicar-se, mortalidade, a capacidade de crescer, uma conduta social, um código moral, etc. (DESCOLA, 2001: 101, Minha tradução)

Esta é uma constatação que as cosmologias nativas têm um nível de complexidade para as quais a antropologia deve buscar novos recursos de compreensão pela variedade de estilos sociais e suas interações culturais. Descola (2001) no trecho acima está preocupado em mostrar que as ferramentas clássicas da teoria antropológica não são suficientes, embora importantes, para investigar as cosmologias nativas e também buscar novas ferramentas para isso. Assim, é importante não fazer oposição radical entre o natural e o social. Neste contexto, as categorias êmicas devem ser tomadas como elementos da cosmologia.

O mesmo trecho também, dá um elenco daquilo que pode ser considerado não humano, trata-se de um elenco de seres dotados de significados que não se encaixam em uma lista hermética de classificação tal como natural e não natural como nas classificações naturalistas. Na Amazônia tudo aquilo que entra em relação humana passa a ser uma entidade social em que a natureza oferece uma gama de seres com essas características. Como estes variados seres adquirem natureza social e qual a origem desses significados? Tanto os clássicos da literatura antropológica como Durkheim como de estudos mais recentes atribuem à religião como uma fonte desses significados.

Dos fatores espirituais derivam grande parte dos significados como mostra Laraia (2005: 8) "A maior parte do trabalho dos xamãs consiste em efetuar curas através do controle dos espíritos que provocam as doenças e, até mesmo, a morte”. Com isso, o transcendente é parte importante da cosmologia indígena da Amazônia e também da religiosidade popular que aí se desenvolveu. Isto quer dizer que as entidades espirituais não estão dissociadas da natureza mas ambas fazem parte da mesma realidade.

Laraia também mostra que os Tupis tinham a ideia de um ser superior Mahyra, mas que não se compara ao Deus cristão eterno e criador (Idem, 2005: 12), no entanto, entre eles existem características comuns pois são entidades espirituais que se relacionam com mundo humano. Com a chegada de outros povos na Amazônia europeus e africanos, o sistema cosmológico diversificou-se ainda mais, como mostra Maués (2012: 38): 
O sistema cosmológico - uma bricolage de múltiplas concepções - inclui diferentes planos com seus personagens fundamentais: bem acima (no céu), Deus, anjos, santos, espíritos de luz e "anjinhos" (que morreram crianças). No espaço intermediário, entre o céu e a superfície terrestre, ficam os espíritos maus (uma espécie de demônios, incluindo Satanás) e os espíritos penitentes (que passam por provações, antes de poderem atingir a salvação, no plano superior). Na superfície terrestre habitam os seres humanos (entre o nascimento e a morte), os outros animais e as plantas. No "fundo" - das águas e da terra - fica o lugar do "encante": é a morada dos encantados que, no entanto (e de várias maneiras), relacionam-se com os humanos que moram na superfície. Os encantados são vistos também como seres humanos (não são pensados como espíritos), porque não morreram, mas se encantaram. Os dois mais importantes são o Rei Sebastião e Norato Antônio (Cobra Norato), mas há muitos outros personagens, inclusive princesas, entre as quais se destacam as filhas do Rei Sebastião.

Maués ao mostrar a vastidão da cosmologia religiosa presente em várias localidades do Pará constata que esta realidade social só pode ser melhor estudada superando a dicotomia natureza cultura, mas que necessita de uma visão desta realidade em perspectiva: “aproximando a visão de mundo e a compreensão adotada por essas populações do perspectivismo indígena analisado nos trabalhos de Eduardo Viveiros de Castro" (Idem, 2012: 55). É importante a análise de Maués ${ }^{4}$ pois ele estende a teoria do perspectivismo indígena de Viveiros de Castro para compreender a religiosidade popular.

É salutar ressaltar que para Maués, a aplicação da teoria de Viveiro de Castro, no caso deste artigo à religiosidade popular, não corresponde inteiramente com as questões dos índios de origem tupi na Amazônia, havendo variações. Um pressuposto de tomo é aquele que Maués mostra que o perspectivismo não é somente indígena pois retrata uma condição fundamental da vida, e o que é importante para esse minha análise, ou seja, de que o perspectivismo não comunga coma a visão dual da vida mas parte do pressuposto de que existem diversas possibilidades de se ver mundo.

Deste modo, em seguida faço algumas reflexões, sobre religiosidade popular, mas especificamente a narrativa de milagres no catolicismo amazônico a partir do perspectivismo.

\footnotetext{
${ }^{4}$ Maués postula a utilização do perspectivismo ameríndio de Viveiro de Castro para temas amazônicos que extrapolam as populações de origem tupi a partir da análise das cosmologia de populações rurais amazônicas feita por Wawzyniak que se baseou, entre outros, na teoria de Viveiro de Castro. Cf: WAWZYNIAK, João Valentin. "Engerar" uma categoria cosmológica sobre pessoa, saúde e corpo. Ilha, Florianópolis, v. 5, n. 2, p. 3355, 2003.Disponível em: <www.periodicos.ufsc.br/index.php/ilha/article/download/.../15348>.
} 


\section{O TESTEMUNHO DE MILAGRES COMO EXPRESSÃO DA COSMOLOGIA AMAZÔNICA}

Para iniciar a reflexão sobre a posição que ocupa um testemunho de tipo religioso é importante ter claro a que tipo de tradição estas narrativas pertencem, quais bases epistemológicas as sustentam, de como o mundo é concebido e ordenado, ou seja, sua cosmologia.

Com essa discussão, o perspectivismo ameríndio ajuda em uma questão antropológica importante, ou seja, que "mundo" é expresso quando se diz que bicho é gente? Vimos que o humano é todo ser capaz relação social e que o corpo é um processo de fabricação e metamorfose. Viveiros de Castro pensa para o nativo uma cosmologia peculiar, uma filosofia da natureza que formula uma ideia de mundo e de suas características gerais. O autor expõe algumas noções cosmológicas dos indígenas: taxonomia dos seres vivos, fabricação e transformação do corpo, o mundo mitológico e histórico e a não separação em categorias entre humanos, animais e espíritos.

Esta cosmologia postula o mundo natural como mutável. O sistema cosmológico ameríndio tem várias dimensões irredutíveis ao dualismo natureza e cultura, pois estabelece uma relação essencial entre estados corporais e estados sociais. O mundo é povoado por seres diversos, esta concepção de mundo tem fundamentos nas narrativas míticas de acontecimentos que narram como era o mundo no início dos tempos e que orientam o mundo atual. $\mathrm{O}$ fazer e o transformar são processos característicos do mito.

Há muito observa-se que o processo de abertura das fronteiras culturais vem se acentuando e teve seu ponto mais alto com a globalização, com os meios de comunicação e transporte modernos e com as migrações que fazem com que indivíduos de diferentes culturas coabitem em um mesmo espaço geográfico onde o choque de cosmologias ou culturas é inevitável. Por exemplo, como sujeitos ocidentais que vivem num mundo tecnológico se relacionam não somente com outros sujeitos mas com outras ideias oriundas de cosmologias distintas? Como os mitos continuam ativos nesse contexto?

Sabe-se que a população das cidades amazônicas foram constituídas por índios autóctones, africanos e europeus, portanto, três cosmologias que são narradas por mitos fundadores. Não é o caso de fazer uma explanação individualizada de cada uma dessas cosmologias, mas ver como essas concepções influenciam no modo de vida amazônico e de orientar o trabalho do antropólogo em relação aos "mundos possíveis" (VIVEIROS DE CASTRO, 2002: 117) expressos pelos nativos. Assim, Viveiros de Castro expressa seu 
objetivo ao levantar tais questões: "Meu objetivo são os conceitos indígenas, os mundos que eles constituem (mundos que assim os exprimem), o mundo virtual de onde eles procedem e que eles pressupõem" (Idem, p. 125).

O autor ajuda a entender que a cosmologia amazônica é formada por um conjunto de conceitos em perspectiva, que pontos de vista extraídos de narrativas míticas demarcam o modo nativo de se comportar no mundo. Um testemunho de milagres deve ser ouvido levando em consideração todos estes aspectos que é chave de interpretação dessas narrativas que permite perceber como o narrador constrói seu próprio evento, ou seja, uma cura milagrosa, um salvamento de uma tragédia ou uma conversão religiosa que ele chama de milagre ou graça alcançada. Estes fenômenos de religiosidade dão sentido a uma realidade social de significados e tornam a vida possível por uma visão de mundo elaborada a partir de um material simbólico em uma realidade concebida como transcendente e divina. Por isso, o campo religioso é um dos estruturadores da visão de mundo na qual narrativas de milagres são possíveis.

As narrativas de milagres sustentam-se com as declarações de seus personagens que com suas experiências interpretam e fazem a história, isto acontece sob a forma de testemunhos. Essa oralidade é um aspecto importante da cosmologia amazônica, é onde se mostra seus conceitos subjacentes aos relatos nativos como "na mata fui enganado por um bicho que tinha a aparência de gente" ou "fui salvo da morte por Nossa Senhora". Por isso, o autor mostra como se deve levar a sério os conceitos nativos: "para crer ou não crer em um pensamento, é preciso primeiro imaginá-lo como um sistema de crenças" (VIVEIROS DE CASTRO, 2002: 130). Na Amazônia tal sistema é composto pelos elementos da cosmologia ameríndia e do catolicismo popular vindo de Portugal que fazem uma cosmologia onde é possível tanto a crença nos mitos amazônicos como nos santos católicos.

\section{CONSIDERAÇÕES FINAIS}

Neste trabalho tentei dar uma nova abordagem às minhas pesquisas sobre religiosidade popular na Amazônia, sobre a qual já tinha refletido sobre aspectos simbólicos das as parições marianas na religião, sobretudo em Belém do Pará, que foi objeto de pesquisa para minha dissertação defendida em 2015 na Universidade do Estado do Pará ${ }^{5}$. Este artigo serviu como aprofundamento de tais pesquisas, em que foram aplicadas duas novas reflexões. A primeira

\footnotetext{
${ }^{5}$ Dissertação que foi publicada pele Editora Paka-Tatu: RAMOS, José Maria Guimarães. A Aparição de Nossa Senhora de Nazaré em Belém do Pará: o sagrado na Amazônia. Belém: Paka-Tatu, 2018.
} 
foi a de Amazônia antropogênica que enfatizou a ideia de relação não dicotômica entre a natureza e o humano na composição tanto da natureza como das sociedades locais. A segunda reflexão foi a fundamentação de que a religiosidade popular expressa nos testemunhos de milagres revela uma cosmologia religiosa não dual, mas de mundos humano, natural e espiritual, possíveis pela análise a partir do perspectivismo, pelo qual é possível múltiplos mundos. Isto permite desvendar porque os devotos católicos podem estabelecer diálogo com seus santos de devoção o que não seria possível com a visão dualista, de dois mundos separados, onde também não seria possível o mundo espiritual e a intervenção de seus habitantes no mundo humano, intervenção como os milagres.

A religiosidade popular tomada como fonte interpretativa da Amazônia hodierna mostra como esses elemento são importantes e têm a contribuir como a reflexão antropológica atual. A ideia de uma Amazônia antropogênica é fundamental para colocar nova luz sobre aspectos da natureza que pareciam resolvidos, mas que na verdade estão longe de se alcançar um compreensão desejada, a região amazônica ainda tem muito a nos ensinar sobre si mesma, alguns autores trabalhados neste artigo nos mostram isso, ou seja, que a cultura amazônica precisa ser mais estuda e que a teoria antropológica precisa alargar seus horizontes.

Um exemplo disso é a antropologia de Viveiros de Castro que formulou o conceito de "perspectivismo ameríndio" trouxe o pensamento nativo de volta ou centro da etnologia indígena amazônica ao tomar as narrativas como enunciados de uma cosmologia que revela o mundo dos nativos e seus conceitos. O ponto de vista do autor vai ao encontro do principal objetivo da antropologia, ou seja, dizer algo das pessoas que pertencem a uma determinada cultura: “dizer que os pecaris são humanos não nos 'diz' nada sobre os pecaris, mas muito sobre os humanos que o dizem". Esta mesma postura pode-se adotar para dizer algo das pessoas que testemunham milagres, sua visão de mundo, sua crença, mitos, símbolos e ritos que dão sentido à existência humana. 


\section{REFERÊNCIAS}

DESCOLA, Philippe; PÁLSSON, Gísli. Introdução. In: DESCOLA, Philippe; PÁlSSON, Gísli (Org.). Naturaleza y Sociedad: Perspectivas antropológicas. Mexico D.F: Siglo veintiuno editores, 2001.

Consturyendo naturalezas: Ecología simbólica y practica social. In: DESCOLA, Philippe; PÁLSSON, Gísli (Org.). Naturaleza y Sociedad: Perspectivas antropológicas. Mexico D.F: Siglo veintiuno editores, 2001.

LARAIA, Roque de Barros. As religiões indígenas: o caso Tupi-Guarani. Revista USP. São Paulo, n. 67, p. 6-13, Set-Nov, 2005.

LOUREIRO, João de Jesus Paes. A conversão semiótica: na arte e na cultura. Belém: EDUFPA, 2007.

MAGALHÃES, Marcos Pereira (Org.). Amazônia antropogênica. Belém: Museu Paraense Emílio Goeldi, 2016.

MAUÉS; Raymundo Heraldo. O Perspectivismo indígena é somente indígena? Cosmologia, religião, medicina e populações rurais na Amazônia. Mediações. Dossiê - Amazônia: sociedade e natureza. n. 1, v. 17, p. 33-61, Jan-Jun, 2012.

RAMOS, José Maria Guimarães. A Aparição de Nossa Senhora de Nazaré em Belém do Pará: o sagrado na Amazônia. Belém: Paka-Tatu, 2018.

TIM INGOLD. EL forrajero óptimo y el hombre económico. In: DESCOLA, Philippe; PÁLSSON, Gísli (Org.). Naturaleza y Sociedad: Perspectivas antropológicas. Mexico D.F: Siglo veintiuno editores, 2001.

VIVEIROS DE CASTRO. Eduardo. O nativo relativo. Mana. Rio de Janeiro. vol. 8. n. 1, abr. 2002. Disponível em: http://www.scielo.br/scielo.php?script=sci_arttext\&pid=S010493132002000100005. Acesso em: 23/09/2016.

WAWZYNIAK, João Valentin. "Engerar" uma categoria cosmológica sobre pessoa, saúde e corpo. Ilha. Florianópolis, v. 5, n. 2, p. 33-55, 2003. Disponível em: $<$ www.periodicos.ufsc.br/index.php/ilha/article/download/.../15348>. Acesso em: 19 mar. 2012.

Recebido em: 15/07/2019

Aprovado em: 10/08/2019 